\title{
Flipping a college physical activity course: Impact on knowledge, skills, and physical activity
}

\author{
Michelle Vaughn ${ }^{1}$, Jung Won Hur ${ }^{2}$ and Jared Russell ${ }^{3}$ \\ ${ }^{1}$ Kutztown University, Department of Sport Management and Leadership Studies, USA(ORCID: 0000-0001-7879-0880) \\ ${ }^{2}$ Auburn University, Department of Educational Foundations, Leadership, and Technology, USA (ORCID: 0000-0002-4138-400X) \\ ${ }^{3}$ Auburn University, Department of Student Development in the College of Education, USA(ORCID: 0000-0002-6534-6286)
}

\begin{abstract}
The purpose of this study was to examine the impact of a flipped classroom model on students' knowledge, skills, and physical activity in a collegiate physical activity course. While there are many studies exploring the impact of the flipped classroom in various fields of study, a dearth of studies has examined the impact of this new pedagogy in a physical education course. We thus flipped a college level physical education course and examined students' learning experiences. Students were required to watch health knowledge and exercise skill videos prior to a class and engage in active physical activity both inside and outside the classroom. Multiple data were collected to examine the impact, including pre- and post- knowledge and skill tests, individual interviews, student surveys, and physical activity logs. The findings demonstrated that students' health knowledge and exercise skills were significantly improved, and the course allowed students to be engaged in various types of physical activity inside and outside the classroom.
\end{abstract}

Keywords: Flipped classroom; Physical education; Physical activity; College students; Instructional strategies

Article History: Submitted 9 August 2019; Revised 24 October 2019; Published online 26 October 2019

\section{Introduction}

Regular physical activity has many benefits, including reducing the development of cardiovascular disease, cancer, and feelings of depression as well as promoting psychological well-being (Lee et al., 2007). Despite its importance, the numbers of four-year colleges and universities that provide physical education have declined from $97 \%$ in the 1920 s to $39.55 \%$ in 2010 (Cardinal, Sorensen, \& Cardinal, 2012). One in three college students tend to become less physically active throughout college, resulting in weight gain at a rate of almost six times that of the general population (Small et al., 2013). More recently, Pope, Hansen, and Harvey (2017) examined college students' weight trajectory throughout their four years and found that both body mass index and the weight of 86 students were significantly higher at the end of their senior year.

The American Medical Association declared obesity as a disease in 2013, and it has mobilized several professional health organizations to heighten health awareness and quality of life for all

\footnotetext{
Address of Corresponding Author

Michelle Vaughn, Ph.D., Kutztown University, 217 Old Main, Kutztown PA 19530, 484-646-5830.

$\triangle$ vaughn@kutztown.edu
}

How to cite: Vaughn, M., Hur, J. W., \& Russell, J. (2019). Flipping a college physical activity course: Impact on knowledge, skills, and physical activity. Journal of Pedagogical Research, 3(3), 87-98. 
(Fryhofer \& Martin, 2013). It also reinvigorated physical education educators to further investigate and encourage more effective pedagogical practices for application in the field to promote physical activity in a physical education course (Kohl III \& Cook, 2013).

A new pedagogical practice that can be effectively implemented to promote physical activity in college-level physical activity courses is the flipped classroom model. This model is a technologysupported pedagogical approach, which supports active learning in classrooms (Lo \& Hew, 2017). This new approach allows instructors to have more activity time in the class by providing lecture content in the form of online videos in advance. Students who are taking physical education courses often do not have enough time for excises in the class due to the amount of time needed for a class lecture. By adopting the flipped classroom model, students can have more physical activity time while also attaining required knowledge and skills. Although many researchers have examined the impact of the flipped classroom model in various fields such as science (Ryan \& Reid, 2016) and business (Albert \& Beatty, 2014), a lack of studies has explored the impact of this new approach in the collegiate physical activity field. Thus, this study aimed to examine the impact of the flipped physical education classroom on college students' knowledge, skills, and physical activity.

\subsection{Theoretical Framework}

\subsubsection{Flipped classroom model}

The flipped classroom model, also known as the inverted classroom model, is different from the traditional classroom in two ways. First, it replaces standard lectures with active and studentcentered learning activities. Second, it provides students with outside learning opportunities to learn new concepts by watching recorded lectures or listening to podcasts (Long, Logan \& Waugh, 2016).

McNally et al. (2016) listed four elements that constitute flipped classroom: (a) resources that help students learn content prior to a class (e.g., recorded online videos), (b) strategies to help students prepare for a class (e.g., quiz, discussion questions), (c) a mechanism to evaluate students' understanding (e.g., graded quiz), and (d) in-class activities that focus on student-centered learning. Lo and Hew (2017) argue that the flipped classroom model is a feasible strategy that can meet the needs of diverse learners. Slow learners can pause or replay instructional videos for comprehension. Students who already know the content can skip some part of an instructional video to save time. Teachers can use the class time for differentiated instruction. Instead of providing a large group lecture, teachers can provide one-on-one help while students are engaged in collaborative activities.

The flipped classroom model is being researched by educators to examine the effectiveness of this instructional model. For instance, Mason, Shuman, and Cook (2013) compared the effectiveness of an inverted classroom and a traditional classroom in an engineering course. They reported that more content was covered in the flipped classroom model, and test scores of students in the flipped classroom model were equal or higher than scores of their traditional classroom cohorts. Park and Park (2018) provided 81 junior nursing major students with a flipped classroom experience and examined students' learning outcomes and the level of critical thinking skills. The findings presented that the scores of students' subject learning and critical thinking skills demonstrated a greater level of increase than those of their controlled counterparts. Wilson (2013) flipped an undergraduate statistics course and reported that she was able to remove much lecture time and create an active learning environment where she can provide immediate feedback. The overall course grades of the flipped class were higher than those of two previous sections taught in a traditional manner.

While there were many studies demonstrating positive outcomes, not all studies observed similar effects. Lents and Cifuentes (2009) flipped a college level biology course, and the findings yielded no statistical difference between video lectures and in-class lectures. After administering a post experiment survey, they discovered that the poor delivery method of the online videos caused 
students to have trouble staying focus. Chen, Lui, and Martinelli (2017) calculated the effect size of nine (9) controlled flipped classroom studies in medical education and presented that the effect of the flipped classroom model on changes in knowledge and skills was less conclusive: Cohen's D effect size ranged from -0.27 to 1.21 . They asserted that the flipped classroom model is a promising teaching approach when the goal is to promote student's motivation and engagement. However, the effect on changes in knowledge and skills are inconclusive and more research is needed in this area.

Scholars have suggested several strategies for the successful implementation of the flipped classroom model. Sletten (2017) found that some students did not know how to effectively interact with video lectures and were not prepared to learn independently. She suggested modeling selfregulated learning strategies (e.g., rehearsal strategies, elaboration strategies) when interacting with video lectures. The instructors could also view the first few video lectures in the class with student to demonstrate how to study with the video lectures. Moore (2013) suggested several strategies related to creating active learning with online videos, including asking a question at the beginning of the videos to get students thinking critically and embedding short graded quizzes or self-assessments within or at the end of the videos. Bergmann and Sams (2012) suggested a shortlecture video about 5 to 15 minutes. They said, "We have found that chunking the video into smaller segments helps the students learn better" (p. 99). Mok (2014) claimed that instructors should not spend too much time to create "perfect" videos and encouraged them to use existing and free videos that are freely available online.

\subsubsection{Physical activity and physical education}

American Heart Association and American College of Sports Medicine (ACSM) recommends that adults need to engage in moderate-intensity cardiorespiratory exercise training for $\geq 30$ minutes at $\geq 5$ days per week or vigorous-intensity cardiorespiratory exercise training for $\geq 20$ minutes 3 days or more per week. Adults should also perform resistance exercises $\geq 2$ times per week (ACSM, 2011). Unfortunately, many young adults struggle to engage in healthy lifestyles and gain weight faster than their parents (Nanney et al., 2015). Studies examining college students' physical activity found that only one third of college students were reportedly participating in at least 3 days of moderate physical activity, and over $25 \%$ of students were classified as overweight and obese (Keating et al., 2011).

College physical education courses can promote students' physical activity levels, knowledge, and exercise techniques (Sacko et al., 2017). One of the goals of physical education is to encourage and foster physical activity participation inside and outside of class and throughout their lifespans. While a satisfying physical education experience is important to promoting physical activity outside of class, studies have shown that there were several issues in physical education classrooms. A study by Fox, Cooper, and McKenna (2004) indicated that the average physical education time did not satisfy ACSM physical activity recommendations, and that passive classroom activities accounted for $25 \%$ of the class time spent. Mohr, Sibley, and Townsend (2012) identified issues related to physical activity courses, including "poor classroom management for loss in activity time, lack of a wide variety of activities, failure to address practical and applicable health related fitness content, lack of physical and intellectual challenges within lesson plans, and disconnection with classmates" (p. 295). Studies examining barriers to physical activity participation found that the lack of variety of activities in physical education was one of the key reasons why students did not engage in a physical education class. Students wanted to perform a variety of activities that would meet their specific interest, but limited activities were offered within the class sessions (Curry, Jenkins, \& Weatherford, 2015; Domville et al, 2019; Gómez-López, Gallegos, \& Extremera, 2010).

In physical education, there is a need for a pedagogical approach that could be used to resolve the aforementioned problems. The flipped classroom can be one effective pedagogical approach to provide more physical activity time in class as well as offer various engaging activities in the 
classrooms. Furthermore, a successfully flipped physical education class could also increase students' enjoyment of physical activity.

\subsubsection{Purpose of the study}

While there are many studies exploring the impact of the flipped classroom in various fields of study, a dearth of studies has examined the impact of such new pedagogy in a physical education course. It is the researchers' belief that the flipped classroom approach can effectively tackle the lack of practice time and lack of variety issues in physical education classrooms, and that more studies should investigate the impact and students' perceptions of this new approach. Consequently, the researchers designed a flipped classroom approach in a college level physical education course and explored the impact. The following two research questions guided the study:

(a) To what extent does the flipped physical education classroom have an impact on college students' knowledge, skills, and physical activity?

(b) How do students perceive their experiences of the flipped physical activity classroom?

\section{Method}

\subsection{Participants}

The participants consisted of 45 college students attending a research university located in the Southeastern Region of the United States. There were 33 female and 12 male students of which 39 were Caucasian and 6 were African American. The participants varied in classification and majors that included 11 freshman, 9 sophomore, 12 juniors, and 13 seniors. A total of 18 students majored in STEM (Science, Technology, Engineering and Mathematics), while 14 students majored in education. The majors of the remaining students varied and included business, liberal arts, and human science. Approximately $49 \%$ of them reported that they were physically active at least three days per week.

\subsection{The Case: Flipped Physical Education Course}

In order to provide more physical activity time inside and outside the classroom, the researchers flipped a collegiate muscular strength, flexibility, and cardiorespiratory fitness physical education course. This course consisted of both low and high level skills and physical activity movement, along with a conceptual aspect, which was made appropriate for the implementation of a flipped classroom lesson. The course was designed to help students not only develop knowledge and skills but also understand the importance of maintaining a healthy and active lifestyle. The course met three days (Monday, Wednesday, and Friday) per week for 50 minutes and consisted of thirteen (13) exercise skills including squat, lunge, and shoulder press.

The first author, who had two-year experience of teaching the same course, designed the flipped course and another instructor delivered the course. The flipped lessons each week consisted of three components: (a) pre-online learning, (b) active classroom learning, and (c) outof-class exercise day. The pre-online learning included one lecture video related to Health Related Fitness Knowledge (HRFK). The content was divided into 10 video lessons, and each week's video focused on a different lesson. Lesson topics included physical wellness and nutrition, prescriptions for wellness, and writing personal exercise goals and programs. The health concepts were presented in videos and voice-over PowerPoint presentations featuring practical examples and detailed explanations of the concepts. Pre-online learning was also accompanied with skill videos demonstrating the correct techniques of the 13 exercise skills, one or two skill(s) per week. Students were required to watch both the lecture and skill videos and to take online quizzes that examined their understanding of the knowledge and skills prior to the beginning of a class each week.

Students participated in the exercise skills demonstrated in the weekly videos during a class, and the instructor provided corrective feedback when necessary. The administration of online exercise skill videos was based on the exercise routine performed during a class session each week. 
For instance, when the exercise routine incorporated several movements such as squat and lunge, those videos were assigned for students to watch before the class. During the sessions, the instructor assisted students in performing the skills correctly in the classroom when necessary. The skill videos were accessible throughout the semester to help students review them at any time.

In order to help develop lifelong healthy behaviors, students were given an "out-of-class exercise day" each week. Instead of coming to the class on Fridays, they were encouraged to participate in a group fitness class of their choice, available at the university wellness center for free, or engage in other physical activity such as hiking and running. Students were required to submit exercise log sheets documenting the types of exercise and the amount of time they were engaged in the exercise during the out-of-class exercise days.

\subsection{Data Sources}

One-group pretest-posttest design was used, and six different types of data were collected to determine the effect of flipped classroom. First, students' knowledge of health concepts was measured using HRFK test adopted from the FitSmart test (Zhu, Safrit, \& Cohen, 1999). Second, the techniques for the 13 exercise movements were measured using the rubrics developed by the National Strength and Conditioning Association manual (Sands, Wurth \& Hewit, 2012). Third, all students were given a Gopher FITstep Pedometer, which measured exercise intensity with step count, activity time, and moderate to vigorous physical activity (MVPA). Fourth, exercise log sheets were collected to examine the physical activity students were engaged in during out-of-class activity days (one per week, twelve in total). Fifth, classroom observations occured each class session to explore specific activities students were engaged in during the class. Sixth, a course satisfaction survey adopted from Tosta (2012) was administered to explore students' perceptions of the flipped classroom. Finally, individual semi-structured interviews took place with 15 students. The interview questions examined students' experiences and perceptions of online lectures, classroom physical activity, and out of class exercise day. The interview questions included, "Tell me about what you liked and disliked about the online lecture videos." and "Describe what it was like to be given one of your assigned class days to do exercise on your own.".

\subsection{Procedures}

After receiving approval from the Institution Review Board (IRB), the course preparation meetings were conducted several times prior to the start of the semester with the instructor who taught the course to help her to become familiarized with the course structure. A course orientation on the flipped classroom was provided to students in the first week to help students learn how to review online video lessons and take online quizzes. The knowledge and skill pre-test were conducted during the second week after receiving consent from students. Classes were also observed throughout the semester, and informal conversations with students frequently occurred while the classes were being observed. Pedometers were given to all students for two weeks while they were engaged in weighted exercise and cardiorespiratory exercise sessions. Since there were other instructors in the program that also used the pedometers frequently, we were only able to use them for those two weeks.

The post knowledge and skill test along with course satisfaction survey took place during the week 15 and 16 of the semester. Individual interviews were conducted at the end of the course with 15 participants who were willing to be interviewed. They were given the option to select a date and time convenient for them to participate in the interviews. Once these dates and times were finalized, a small conference room was used to conduct the interviews. The participants were assigned pseudonyms to maintain confidentiality of their information during the data collection and analysis process. 


\subsection{Data Analysis}

Both quantitative and qualitative analyses were performed using IBM Statistical Package for the Social Sciences (SPSS) version 21 and Atlas.ti 7 software respectively. In order to examine knowledge and skill improvement, the paired sample t-test was used for the analysis of pre- and post- HRFK test as well as 13 exercise skill tests. Descriptive statistics were used to analyze the course satisfaction survey and pedometer data. Content analysis (Krippendorff, 2004) was conducted to analyze the survey open-ended questions. While we reviewed students' answers, we identified common themes and calculated the frequency of the themes.

The semi-structured interviews were transcribed, and then the researchers applied descriptive coding and in vivo coding (Saldaña, 2009) while reading the interview data and field observation notes. During the data analysis, the researchers noted specific reasons as to whether students were either satisfied or not satisfied with the flipped classroom model. To identify the possible reasons, each student's interview data, open-ended answers, and common themes across the data were compared. Peer reviews occurred when the data and themes were shared with other graduate researchers.

\section{Results}

\subsection{Impact of Flipped Classroom: Knowledge, Skill, and Physical Activity}

The paired sample t-test was used to determine whether there was a difference between students' pre- and post-test scores on the HRFK test. The results of the post-test scores $(\mathrm{M}=23.27, \mathrm{SD}=2.10)$ was higher than the pre-test scores $(\mathrm{M}=22.09, \mathrm{SD}=2.68)$. The difference was statistically significant: $t=3.15, p<.05$. Cohen's $d$ was calculated at 0.49 , demonstrating a medium effect (Cohen, 1988).

A paired sample t-test was conducted to examine if there was a difference between students' pre- and post-test scores on 13 exercise skills. The findings demonstrated that the total post-skill scores $(M=131.05, S D=3.838)$ were higher than total pre-skill scores $(M=126.36, S D=3.567)$. The difference was also statistically significant, $t=10.078, \mathrm{p}<.05$, Cohen's $d=1.27$. When analyzing the 13 exercise skill techniques individually, the differences of 7 skills (squat, back extension, push-up, lunge, triceps kick-back, sit-up, and shoulder press) were statistically significant, while no statistical significance was found on six (6) skills (deadlift, bicep curls, hip abduction, bent-over rows, bench press, and calf-raises).

The analysis of the field notes and pedometer data indicated that the flipped classroom allowed students to actively engage in various types of physical activity in the classrooms. Since the online videos presented the health concepts and corrective techniques, the instructor did not need to spend much time for large group lectures or demonstrations. The field notes described that the instructor usually spent less than 10 minutes for class announcements and questions, and students had more than 40 minutes for warm-up and to perform the day's exercise routine.

Students engaged in warm-up activities such as jogging, stretching, and/or lunges. Following the warm-up, students were often paired in groups or with a peer to complete the day's exercise routine. The instructor walked around the room to observe students' execution of the skills and provided corrective feedback as necessary. At various periods throughout the course, some students requested that the instructor demonstrated or modeled some of the more complex exercises such as burpees or bent over rows repeatedly to get an understanding of how the exercises were performed.

The analysis of the pedometer data revealed that students actively engaged in physical activity during these class sessions (See Table 1). Students took fewer steps per minute on average during their weighted exercise routine $(\mathrm{MVPA}=9.47)$ than when they participated in cardiorespiratory exercise (MVPA $=32.59$ ). The innate structure of weighted exercises where movements are often static may have accounted for the low MVPA level in this case. 
Table 1.

Student Physical Activity Level in the Flipped Classroom

\begin{tabular}{llccc}
\hline Types of Exercise & \multicolumn{2}{c}{ Weighted Exercises } & \multicolumn{2}{c}{ Cardiorespiratory Exercise } \\
\hline Measures & Mean & SD & Mean & SD \\
\hline Step Count & 1653 & 271.83 & 4625.56 & 1438.25 \\
\hline Activity Time & 11.98 & 2.07 & 35.17 & 8.86 \\
\hline $\begin{array}{l}\text { Moderate to Vigorous } \\
\begin{array}{l}\text { Physical Activity } \\
\text { (MVPA) }\end{array}\end{array}$ & 9.47 & 1.55 & 32.59 & 8.67 \\
\hline
\end{tabular}

One noticeable finding from the observation notes was that the instructor was able to teach an additional 16 skills beyond the 13 exercise skills that were originally planned. The additional skills that the instructor was able to incorporate included wheel barrow, farmers carry, burpees, walking with kettlebells, head cutters, stadiums, and circuit championship. In other traditional classrooms, these skills were not typically incorporated due to the lack of time, but the instructor in the flipped class in this study was able to integrate various additional skills in her class throughout the semester.

In order to examine the types of activities and exercise time that students were engaged in on the out-of-class exercise days, we analyzed students' exercise logs. The findings demonstrated that students participated in 25 different activities including Zumba, swimming, basketball, and trail running. For each activity, students demonstrated active physical activity participation for approximately 30 minutes to 90 minutes.

\subsection{Students' Perceptions}

The analysis of the course satisfaction survey indicated that students were highly satisfied with the flipped physical education classroom (see Table 2). Overall, 95\% of students indicated that they were satisfied with the way the course content was taught. Over $97 \%$ of students expressed that they enjoyed the autonomy that the course provided, and $91 \%$ of students indicated that the course allowed enough time to practice in class.

Table 2.

Course Satisfaction Survey Results $(n=45)$

\begin{tabular}{|c|c|c|c|c|c|c|}
\hline \multirow[t]{2}{*}{ Variables to measure satisfaction } & \multicolumn{6}{|c|}{$\begin{array}{l}\text { Scores on the 5-point Likert Scale } \\
\text { (\% Respondents) }\end{array}$} \\
\hline & 5 & 4 & 3 & 2 & 1 & $\mathrm{~N} / \mathrm{A}$ \\
\hline I am satisfied with the way the course content was taught & 30 & 11 & 2 & 0 & 0 & 0 \\
\hline $\begin{array}{l}\text { I liked the techniques used by the teacher to teach the } \\
\text { unit }\end{array}$ & 35 & 7 & 3 & 0 & 0 & 0 \\
\hline $\begin{array}{l}\text { The online delivery format was appropriate for course } \\
\text { materials }\end{array}$ & 25 & 13 & 6 & 1 & 0 & 0 \\
\hline I enjoyed autonomy that the course provided & 27 & 17 & 0 & 0 & 0 & 1 \\
\hline I enjoyed activities used in the course & 30 & 13 & 2 & 0 & 0 & 0 \\
\hline Learning was enhanced with online content/material & 27 & 8 & 9 & 1 & 0 & 0 \\
\hline The course allowed for enough time to practice in class & 36 & 5 & 4 & 0 & 0 & 0 \\
\hline
\end{tabular}

The interview data also demonstrated that students were satisfied with the overall course structure. Jeff (Senior, Business major) said, "I like the structure of the class. I like the exercise routine that we do. We don't do the same exercises every day, which is nice." Claire (Junior, Liberal Arts major) also shared a similar opinion. She said, "I think this class was enjoyable. I think 
the quizzes outside of class are necessary, and I loved doing the different exercises instead of one standard thing every class."

Further analysis indicated that two components, out-of-class exercise day and online videos, particularly contributed to the high course satisfaction. Many students emphasized that their favorite activity was to have the out-of-class exercise day because it allowed them to choose what they wanted to do and to develop healthy behaviors. Sue (Freshman, Education major) expressed:

I like the Friday free day because I am not going to be in this class forever and I am not going to always have an instructor telling me what to do. I am going to have to do it on my own. Friday was a kind of the day that I try to do what we would do in class. It kind of taught me how to structure the workout too, so that was nice.

James (Junior, STEM major) echoed how the out-of-class exercise day was helpful to develop a personal exercise habit. He said, "I like the way the course was set up and then having the Friday off. We can take what we learn and structure it into our own program and our own workout and apply it."

Students also shared that the self-exploration opportunity allowed them to participate in a variety of activities offered by the school's wellness center, and they enjoyed the flexibility. Kim (Junior, STEM major) expressed:

I like the free days because I could swap my activities around. The student wellness center has different things for different times and I do whatever is going to fit into my schedule... I like the yoga classes, kick boxing, and they actually have an aqua circuit class in the pool. I have been trying to do as much as I could do.

Another reason students liked the flipped classroom was because of the online videos. Students who took other physical education courses were particularly vocal about the online videos because other courses asked students to use a text-based online portal for content learning. Luke (Sophomore, Education major) said, "I would prefer what we do in this class to the portal. The portal is a lot of reading and it doesn't give you any examples or videos. It is just you reading it." Mike (Junior, Education major) also made a similar comment. He said, "I like this class because of the videos. The portal didn't have the videos. It wasn't really like telling you how to do the exercises." According to the course satisfaction survey, $84 \%$ of the students expressed that they enjoyed the lecture videos.

The analysis of open-ended answers illustrated that students liked that the class emphasized healthy living and the information on videos was useful, interesting, and helpful. The students' perceptions of the skill videos were very positive as well. Even though some of the students were familiar with the exercise routines, they stated that the exercise videos were helpful. Kim (Junior, STEM major) explained:

I actually played softball in high school and we did weight training and all those exercises. I was surprised that we weren't doing some of the things the way we were supposed to do with proper technique... so it was kind of interesting to see the actual way to do it, the right way.

Participants particularly emphasized how the videos helped them learn a correct form. Doug (Junior, Education major) said, "I found I wasn't so big on watching videos in the beginning but once I did, I actually enjoyed them. They are really helpful for form and technique." Some students indicated that they shared the videos with other friends.

While students' perceptions were positive in general, some students shared some negative opinions. About $16 \%$ of the students shared that they did not like the lecture videos. They thought the lecture videos were "boring and uninteresting" and the nutrition video and flexibility video did not apply to them personally. These students explained that they had prior experience of learning exercise and health content and had taken a similar course before. Students who were health or science majors particularly indicated that the information was repetitive. 
There were also approximately $5 \%$ of students who did not like the idea of watching the skill videos online. They expressed that they would have rather the teacher demonstrated the skills in class. Additionally, approximately $7 \%$ of the students claimed that they did not like having a day off and were required to do exercise on their own. They would prefer to be in a class where they are given some structure and being told what to do.

\section{Discussion}

The purpose of this study was to examine the impact of the flipped classroom model in a college physical education class. The results illustrated that the flipped classroom approach helped students develop exercise skills and knowledge and provided them with more practice time in class. Because class time was not primarily spent on lectures or skill demonstrations, the instructor was able to incorporate additional skills into daily class sessions, allowing students to be engaged in a variety of physical activities. The students were presented with various exercises throughout the course, which provided them with the necessary activity challenges they needed. Students reported 30-90 minutes of physical activity engagement during the out-of-class exercise day, and the flipped classroom approach helped students meet their daily physical activity requirements recommended by ACSM (2011).

The findings suggest that incorporation of the flipped classroom model is one effective way to solve issues in collegiate physical education courses. Previous studies have reported issues with physical education such as limited activity time, lack of variety in activities, and lack of challenges (Fox, Cooper \& McKenna, 2004; Mohr, Sibley, \& Townsend 2012). The results of this study revealed that the flipped classroom model allowed the instructor to allocate more time for physical activity and for incorporation of various activities that fit into individual students' needs and interest. Previous studies examining the impact of flipped classroom have also demonstrated positive effect, including more content teaching (Mason, Shuman, \& Cook, 2013), higher test-scores (Park \& Park, 2018), more class engagement (Mok, 2014) and providing more immediate feedback (Wilson, 2013). Based on these positive findings, we recommend that physical education instructors flip their courses to provide students with an active and personalized learning environment.

Congruent to the previous studies, the findings of this study also demonstrated that students were overwhelmingly satisfied with the course structure, content, and class activities. The researchers believe that the instructional strategies incorporated contributed to students' high satisfaction. The researchers provided the flipped course orientation at the beginning of the course by demonstrating how to access online videos and clearly explained the purpose of the flipped classroom and course requirements. Another strategy was to use various videos that were rated as high students' interest in order to help students adopt healthy behavior, values, and nutritional choices for a better quality of life (Corbin \& Cardinal, 2008). These video lectures and exercise skills were available online for students to view at their convenience and as frequently as they chose.

In order to promote students' prior learning, Moore (2013) suggested including short graded quizzes within or at the end of the videos. Weekly quizzes related to the knowledge and skill videos to facilitate students' online learning experience were incorporated into the unit. Students received immediate feedback on quizzes and were encouraged to re-take quizzes to help them review the content. As a result of watching the skill videos online prior to performing them in the class, students reported that they felt knowledgeable and adequately prepared to perform the exercises. In accordance with Bergmann and Sams (2012)' suggestion, videos lasting for less than 15 minutes were developed to help students focus on the video content. As the findings indicated, shorter videos were more favorably accepted because students lost focus or interest in the content over lengthy periods of time.

In conjunction with the skills videos, the instructor provided additional demonstrations of the various skills done in class and individual feedback whenever necessary. Skill demonstrations 
through online videos may not be the most effective approach for skill development in physical education if the videos are the solitary source of skill demonstrations that students receive. However, if the videos are amalgamated with supplemental instructions and feedback from an instructor, then the method can be quite successful in improving skill acquisition and performance level as previously reported (Smith, 2004).

Finally, students' high satisfaction of out-of-class exercise day should be noted. Students enjoyed the autonomy to create their own exercise routine and workout on their own for one day each week throughout the duration of the course. The knowledge students attained from the online videos was able to equip them with the capabilities needed to create their personal exercise program on days they work out on their own. Also, encouraging students to participate in physical activity independently was a good practice for cultivating the habit of exercising on their own, beyond their enrollment in the course. Students did not complain about watching the videos and completing the quizzes prior to classes because they appreciated the fact that they were only required to attend the class twice a week and would have an exercise day of their choice. The researchers recommend that other instructors implement a similar schedule based on the findings of this study, that the flexibility promoted students' enjoyment in physical activity and increased students' course satisfaction.

While numerous instructional strategies were implemented in this case study, not every student enjoyed this new pedagogical approach. This implies that different students' needs and preferences should be acknowledged when flipping a course or lesson. To meet the diverse students' needs, instructors must continue to interact with students individually to explore their personal needs and search for various ways to address students' concerns and preference.

\section{Conclusion}

This study implemented a flipped classroom approach in a collegiate physical education course and examined its impact. Increased students' knowledge, skills, and active participation in physical activity inside and outside the classroom along with the high students' satisfaction support the premise that the flipped classroom model is an effective pedagogical method for college level physical education courses. The researchers highly recommend developing and implementing varying classroom activities that are engaging in order to foster enjoyment and active participation in physical activity. Active and enjoyable classroom engagement could lead to the development of healthy lifestyles, which is the goal of physical education.

While the study demonstrated many advantages of a flipped college physical education class, it also shared a few limitations. First, although the findings described that students' knowledge, skills, and levels of physical activity were increased, it is still unclear whether the flipped classroom approach led to the positive findings because the study did not include a control group. Future studies need to compare the findings with a control group in order to better measure the effectiveness of this new approach. Second, students' activity levels were not systematically measured using the pedometers, because they were only available for utilization for two weeks. This lack of access prevented the measurement of students' activity levels more frequently in the class. Finally, participants in this course were mostly traditional college students who were in their early 20s and quite comfortable using technology. Generalizing this finding to other college settings with students who share different backgrounds should be made cautiously.

Regarding future studies, the researchers recommend examining how the different genders interact in the flipped classroom because a large component of the class is online and previous research (e.g., Heafner, 2014; Weber \& Custer, 2005) has indicated that males and females respond differently to technology. Understanding how different gender responds to online lectures would be important to nurture all students' engagement and motivation for physical activity. Correspondingly, since more class time in the flipped classroom allows instructors to incorporate technology into physical education classroom, future studies need to examine effective ways to 
integrate technology into physical education class to promote physical activity and student engagement during a class.

\section{References}

Albert, M. \& Beatty, B. J. (2014). Flipping the classroom applications to curriculum redesign for an introduction to management course: Impact on grades. Journal of Education for Business, 89(8), 419-424.

American College of Sports Medicine (ACSM, 2011). Quantity and quality of exercise for developing and maintaining cardiorespiratory, musculoskeletal, and neuromotor fitness in apparently healthy adults: Guidance for prescribing exercise. Medicine \& Science in Sports \& Exercise, 43, 1334-1359.

Bergmann, J. \& Sams, A. (2012). Flip your classroom: Reach every student in every class every day. Eugene, OR: ISTE \& ASCD.

Cardinal, B.J., Sorensen, S. D., \& Cardinal, M.K. (2012). Historical perspective and current status of the physical education graduation requirement at American 4-year colleges and universities. Research Quarterly for Exercise and Sport, 83(4), 503-512.

Chen, F., Lui, A. M., \& Martinelli, S.M. (2017). A systematic review of the effectiveness of flipped classrooms in medical education. Medical Education in Review, 51, 585-597.

Cohen, J. (1988). Statistical Power Analysis for the Behavioral Sciences, 2nd Edition. Hillsdale: Lawrence Erlbaum.

Corbin, C. B., \& Cardinal, B. J. (2008). Conceptual physical education: The anatomy of an innovation. Quest, 60(4), 467-487.

Curry, J., Jenkins, J. M., \& Weatherford, J. (2015). Focus on freshman: basic instruction programs enhancing physical activity. Physical Educator, 72(4), 621-639.

Domville, M., Watson, P. M., Richardson, D., \& Graves, L. E. F. (2019). Children's perceptions of factors that influence PE enjoyment: a qualitative investigation. Physical Education and Sport Pedagogy, 1-13.

Fox, K. R., Cooper, A., \& McKenna, J. (2004). The school and the promotion of children's health enhancing physical activity: Perspectives from the UK. Journal of Teaching Physical Education, 23(4), 338-358.

Fryhofer, S. A. \& Martin, D. W. (2013, June). Action of the AMA House of Delegates 2013 Annual Meeting: Recommendations in Report 3 of the Council on Science and Public Health Report Adopted, and Remainder of Report Filed. Retrieved from: https://www.ama-assn.org/sites/default/files/mediabrowser/public/about-ama/councils/Council\%20Reports/council-on-science-publichealth/a13csaph3.pdf

Gómez-López, M., Gallegos, A. G., \& Extremera, A. B. (2010). Perceived barriers by university students in the practice of physical activities. Journal of sports science $\mathcal{E}$ medicine, 9(3), 374-381.

Heafner, T. (2014, March). Gender Differences in Technology Integration. In Society for Information Technology \& Teacher Education International Conference, 1, 2841-2851.

Keating, X. D., Castelli, D., Castro-Pinero, J., \& Guan, H. (2011). University student meeting the recommended standards of physical activity and body mass index. Journal of Research, 6(1), 20-26.

Kohl III, H. W., \& Cook, H. D. (Eds.). (2013). Educating the student body: Taking physical activity and physical education to school. National Academies Press.

Krippendorff, K. (2004). Content Analysis: An introduction to its methodology (2nd ed.).

Thousand Oaks, CA: Sage.

Lee, S. M., Burgeson, C. R., Fulton, J. E., \& Spain, C. G. (2007). Physical education and physical activity: Results from the School Health Policies and Programs Study 2006. Journal of School Health, 77, 435-463.

Lents, N. H., \& Cifuentes, O. E. (2009). Web-based learning enhancements: Video lectures through voice-over PowerPoint in a majors-level biology course. Journal of College Science Teaching, 39(2), 38-46.

Lo, C. K. \& Hew, K. F. (2017). Using 'first principles of instruction' to design secondary school mathematics flipped classroom: The findings of two exploratory studies. Journal of Educational Technology \& Society, 20(1), 222-236.

Long, T., Logan, J. \& Waugh, M. (2016). Students' perceptions of the value of using videos as a pre-class learning experience in the flipped classroom. TechTrends, 60(3), 245-252.

Mason, G. S., Shuman, T. R., \& Cook, K. E. (2013). Comparing the effectiveness of an inverted classroom to a traditional classroom in an upper-division engineering course, IEEE Transactions on Education, 56(4), 430435.

McNally, B., Chipperfield, J., Dorsett, P., Del Fabbro, L., Frommolt, V., Goetz, S., Lewohl, J., Molineux, M., Pearson, A., Reddan, G., Roikos, A., \& Rung, A. (2016). Flipped classroom experiences: Student 
preferences and flip strategy in a higher education context. The International Journal of Higher Education Research, 73(2), 281-298.

Mohr, D.J., Sibley, B.A., \& Townsend, J.S. (2012). Student perceptions of university physical activity instruction courses taught utilizing sport education. Physical Educator, 68(3), 289-309.

Mok, H. N. (2014). Teaching tip: The flipped classroom. Journal of Information Systems Education, 25(1), 7-11.

Moore, E. A. (2013, May 20). From Passive Viewing to Active Learning: Simple Techniques for Applying Active Learning Strategies to Online Course Videos. Retrieved from Faculty Focus: http://www.facultyfocus.com/articles/teaching-with-technology-articles/from-passive-viewing-toactive-learning-simple-techniques-for-applying-active-learning-strategies-to-online-course-videos/

Nanney, M. S., Lytle, L. A., Farbakhsh, K., Moe, S. G., Linde, J. A., Gardner, J. K., \& Laska, M. N. (2015). Weight and weight-related behaviors among 2-year college students. Journal of American College Health, 63(4), 221-229.

Park, E. O. \& Park, J. H. (2018). Quasi-experimental study on the effectiveness of a flipped classroom for teaching adult health nursing. Japan Journal of Nursing Science, 5(2), 125-134.

Pope, L., Hansen, D., \& Harvey, J. (2017). Examining the weight trajectory of college students. Journal of nutrition education and behavior, 49(2), 137-141.

Ryan, M. D. \& Reid, S.A. (2016). Impact of the flipped classroom on student performance and retention: A parallel controlled study in general chemistry, Journal of Chemical Education, 93(1), 13-23.

Sacko, R.S., Egan, C., Michael, D., Moore, E., Kaysing, N., Brazendale, K., \& Webster, C.A. (2017) Activity levels of college students enrolled in physical activity courses. American Journal of College Health, 32(3), 163-170.

Saldaña, J. (2009). The coding manual for qualitative researchers. Thousand Oaks, CA: Sage Publications.

Sands, W. A., Wurth, J. J., \& Hewit J. K. (2012). The National Strength and Conditioning Association's (NSCA) Basics of Strength and Conditioning Manual. Retrieved from https://www.nsca.com/contentassets/116c55d64e1343d2b264e05aaf158a91/basics_of_strength_and_con ditioning_manual.pdf

Sletten, S. R. (2017). Investigating flipped learning: Student self-regulated learning, perceptions, and achievement in an introductory biology course. Journal of Science Education and Technology, 26(3), 347-357.

Small, M., Bailey-Davis, L., Morgan, N., \& Maggs, J. (2013). Changes in eating and physical activity behaviors across seven semesters of college: Living on or off campus matters. Health Education \& Behavior, $40(4), 435-441$.

Smith, J. L. (2004). Effects of video modeling on skill acquisition in learning the golf swing Doctoral dissertation. Brigham Young University, UT.

Tosta, M. R. (2012). Measurement of satisfaction with the online and classroom teaching methodologies of graduate students and its implications for academic achievement. Scientific International Journal, 9(3), 1-31.

Weber, K. \& Custer, R. (2005). Gender-based preferences toward technology education content, activities, and instructional methods. Journal of technology education, 16(2), 55-71.

Wilson, S.G. (2013). The flipped class: A method to address the challenges of an undergraduate statistics course, Teaching of Psychology, 40(3), 193-199.

Zhu, W., Safrit, M.J., \& Cohen, A.S. (1999). FitSmart test user manual: High school edition. Champaign, IL: Human Kinetics. 